\title{
Chromatographically separable rotamers of an unhindered amide
}

\author{
Mario Geffe ${ }^{1}$, Lars Andernach ${ }^{1}$, Oliver Trapp ${ }^{2}$ and Till Opatz ${ }^{* 1}$
}

\section{Full Research Paper}

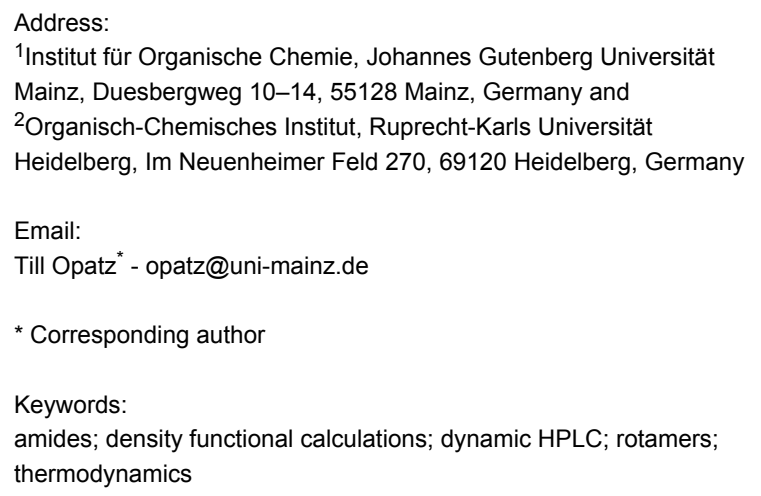

Beilstein J. Org. Chem. 2014, 10, 701-706. doi:10.3762/bjoc. 10.63

Received: 10 January 2014

Accepted: 04 March 2014

Published: 21 March 2014

Associate Editor: J. A. Murphy

(C) 2014 Geffe et al; licensee Beilstein-Institut. License and terms: see end of document.

\begin{abstract}
Surprisingly stable formamide rotamers were encountered in the tetrahydroisoquinoline and morphinan series of alkaloids. We investigated the hindered rotation around the amide bond by dynamic high-performance liquid chromatography (DHPLC) and kinetic measurements of the interconversion of the rotamers which can readily be separated by HPLC as well as TLC. The experimental results of the different methods were compared to each other as well as to results obtained by DFT calculations.
\end{abstract}

\section{Introduction}

The hindered rotation about the amide bond belongs to the most classical concepts taught to every undergraduate chemistry student. However, amide rotamers are generally classified as conformers which interconvert at ambient temperature unless a significant steric hindrance has to be overcome. This is illustrated by another classical textbook example, the coalescence of the NMR signals of $N, N$-dimethylformamide, which can be brought about by gentle warming. Separable amide rotamers are usually regarded as laboratory curiosities and are not expected in the absence of sterical congestion.

During synthetic work in the morphinan series, we encountered a remarkable behavior of an unhindered formamide which produced double bands in TLC. We initially attributed this behavior to the undesired formation of diastereomers as even at $150{ }^{\circ} \mathrm{C}$, no coalescence of the ${ }^{1} \mathrm{H}$ NMR signals of the formyl protons could be observed. However, when the same effect was seen in compound $\mathbf{4}$ possessing only a single stereocenter, the occurrence of highly stable rotamers had to be taken into consideration. Indeed, no change in $R_{\mathrm{f}}$-value of the two discrete spots for compound $\mathbf{4}$ was observed in a two-dimensional TLC experiment in which the second development immediately followed the air-drying of the plate. If one hour at room temperature lay between the first and the second development, two weak off-diagonal spots indicated that interconversion of both species had taken place to a small extent. When the tempera- 
ture was increased to $75^{\circ} \mathrm{C}$ during a 15 min drying period, four spots with roughly equal intensity resulted from the second 2D-TLC run and indicated complete interconversion.

A look into the literature revealed that the occurrence of separable amide rotamers of 1-benzyl- $N$-formyl-1,2,3,4-tetrahydroisoquinolines had been reported independently by Rice, Brossi $[1,2]$ and Szántay [3]. During their investigation of 6'-bromo- $N$ formylnorreticuline, they observed the expected doubling of signals in the ${ }^{1} \mathrm{H}$ NMR spectra as well as a separation of the $E$ and $Z$-rotamers on TLC. Furthermore, they were able to isolate both rotamers in pure form by crystallization. While Rice and Brossi focused on the optical and crystallographic properties of these compounds, Szántay et al. gave a first estimate of the activation energy of the interconversion of these two rotamers based on dynamic NMR spectroscopy at variable temperature. They deduced a value of $94 \mathrm{~kJ} / \mathrm{mol}$ from a coalescence temperature of $170{ }^{\circ} \mathrm{C}$ but did not provide crucial data such as the spectrometer frequency required for the calculation. Sulima et al. reported a rotational barrier of $92 \mathrm{~kJ} / \mathrm{mol}$ for 1 -bromo- $N$ formyl-4-hydroxy-3-methoxymorphinan-6-one based on dynamic NMR while the separation of the enthalpic and entropic contributions to this value was not possible with this method [4].

\section{Results and Discussion Synthesis}

Compound 4 was prepared by $\mathrm{C}$-alkylation of the potassium salt of $\alpha$-aminonitrile 1 with benzyl bromide 2 utilizing methodology established by our group for the syntheses of various isoquinoline alkaloids [5-7]. Spontaneous dehydrocyanation afforded the 1-benzylated 3,4-dihydroisoquinoline which was subsequently reduced in situ to tetrahydroisoquinoline $\mathbf{3}$ in a one-pot procedure with sodium borohydride in $63 \%$ yield. $\mathrm{N}$-Acylation was effected quantitatively by refluxing $\mathbf{3}$ in ethyl formate (Scheme 1).

Dynamic NMR (DNMR) measurements $(400 \mathrm{MHz})$ on a sample of 4 in DMSO- $d_{6}$ at temperatures ranging from $20^{\circ} \mathrm{C}$ to $150^{\circ} \mathrm{C}$, the upper limit for technical reasons, showed no signs of beginning coalescence of the formyl proton resonances even at the highest temperature. This very high rotational barrier prompted us to look for alternative methods which allow the accurate determination of the thermodynamic parameters of the bond rotation. An estimate of the interconversion rate at ambient temperature was obtained from an experiment in which both rotamers of $\mathbf{4}$ were separated by HPLC and their reequilibration was followed with the same technique.

\section{Kinetic studies}

The kinetic studies were performed at $20{ }^{\circ} \mathrm{C}$ on a Knauer normal-phase HPLC (see Supporting Information File 1 for details) using hexane/2-propanol 80:20 as mobile phase. Each rotamer was collected separately and reinjected at defined intervals (7-8 minutes) to follow the interconversion. Equilibrium was reached after $2 \mathrm{~h}$ and the data of the first 50 min were used to determine the initial rate. The integrals were used to quantify the amounts of each rotamer and were plotted as $\ln \left(\mathrm{A} / \mathrm{A}_{0}\right)$ vs time. The slope of the linear regression equates the rate constant $k_{1}$ for a first order interconversion and by using the Eyring equation

$$
\Delta G^{\ddagger}=-R T \ln \left(\frac{k_{1} h}{k_{B} T}\right)
$$

(with $R=$ gas constant, $T=$ temperature, $h=$ Planck constant, $k_{B}=$ Boltzmann constant) the rotational barrier was calculated to $\Delta G^{\ddagger}(293 \mathrm{~K})=92.4 \pm 0.1 \mathrm{~kJ} / \mathrm{mol}(Z$ to $E)$ and $\Delta G^{\ddagger}(293 \mathrm{~K})=$ $93.2 \pm 0.1 \mathrm{~kJ} / \mathrm{mol}$ ( $E$ to $Z$ ) respectively (Figure 1, Figure 2 ).

\section{Dynamic HPLC studies}

Like the DNMR data, the simple kinetic analysis only permits the determination of the free activation energy while the separation of entropic and enthalpic contributions requires a variation of the temperature. Therefore, dynamic high-performance liquid chromatography (DHPLC) [8-10] was performed at temperatures between $20^{\circ} \mathrm{C}$ and $55^{\circ} \mathrm{C}$. The obtained elution profiles were characterized by distinct plateau formation

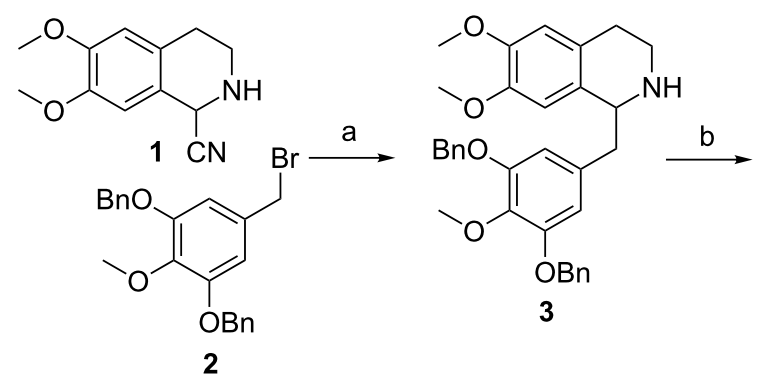<smiles>COc1cc2c(cc1OC)C(Cc1cc(OC)c(OC)c(OC)c1)N(C=O)CC2</smiles><smiles>[Z4][R18]([H])([H])c1cc(C[C@H]2c3cc(OC)c(OC)cc3CCN2C=O)cc(OC)c1OC</smiles>

(mixture of rotamers) 


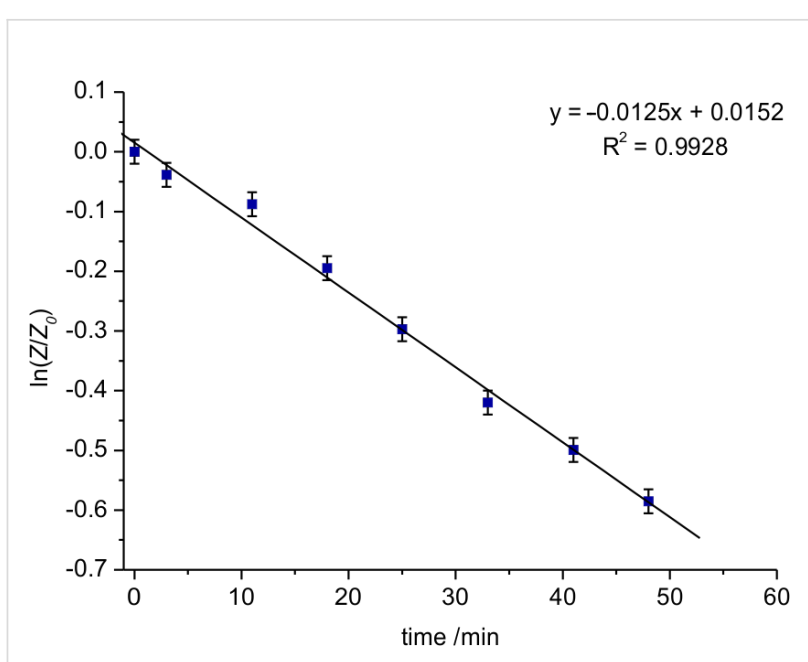

Figure 1: Equilibration of the Z-rotamer of 4 at $293 \mathrm{~K}$

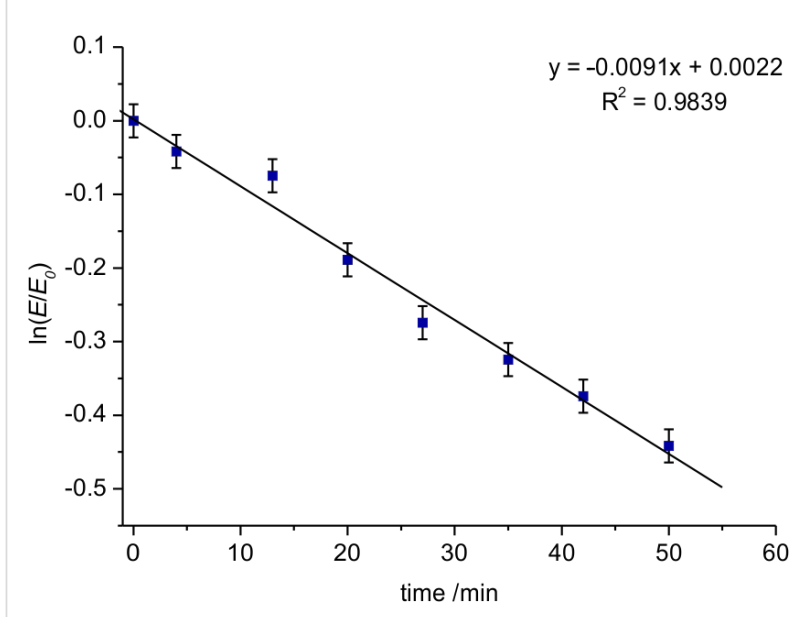

Figure 2: Equilibration of the E-rotamer of 4 at $293 \mathrm{~K}$.

between the well separated peaks of the $Z$ - and $E$-rotamers (first and later eluted isomer, respectively), indicating the interconversion during the partitioning process (Figure 3).
Reaction rate constants $k_{1}$ were determined using the unified equation, which has been described in detail in the literature [11-15]. Calculations were performed with the software DCXplorer [16], which has implemented the unified equation.

For the evaluation of activation parameters of the interconversion process experiments between $30{ }^{\circ} \mathrm{C}$ and $55{ }^{\circ} \mathrm{C}$ were considered, because at lower temperatures the plateau height was too low to be determined with high precision. The Gibbs free activation energy $\Delta G^{\ddagger}(T)$ was calculated according to the Eyring equation (vide supra). The activation enthalpy $\Delta H^{*}$ of the interconversion process was obtained from the slope and the activation entropy $\Delta S^{\ddagger}$ from the intercept of the Eyring plot (Figure 4). Deviations of the activation parameters $\Delta H^{*}$ and $\Delta S^{\ddagger}$ have been calculated by error band analysis of the linear regression with a level of confidence of $95 \%$.

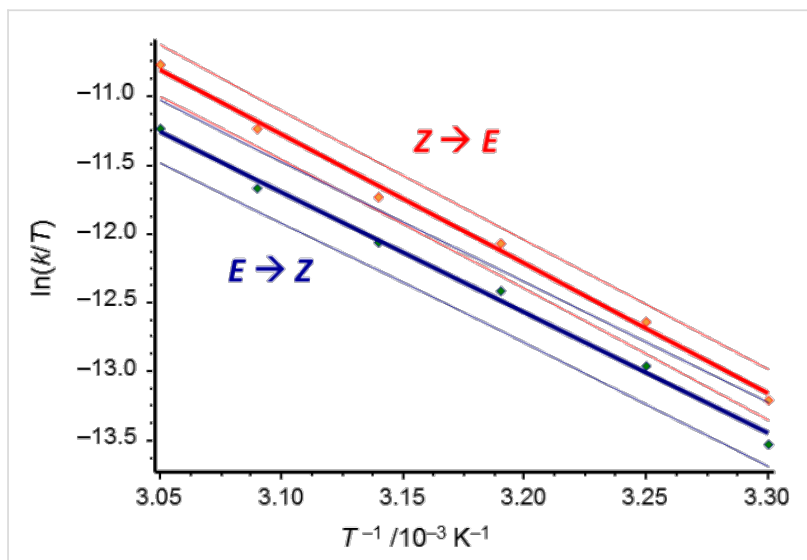

Figure 4: Eyring plot obtained by temperature dependent DHPLC measurements of 4 .

The barriers and activation parameters for the interconversion of the $Z$-rotamer to the $E$-rotamer were determined to be $\Delta G^{\ddagger}(293 \mathrm{~K})=92.5 \mathrm{~kJ} / \mathrm{mol}, \Delta H^{\star}=78.3 \pm 1.8 \mathrm{~kJ} / \mathrm{mol}$ and $\Delta S^{\ddagger}=-49 \pm 2 \mathrm{~J} /(\mathrm{K} \mathrm{mol})\left(\mathrm{R}^{2}=0.9958\right.$, residual deviation $\left.\sigma_{\mathrm{y}}=0.0560\right)$, and for the interconversion of the $E$-rotamer to the $Z$-rotamer $\Delta G^{*}(293 \mathrm{~K})=93.1 \mathrm{~kJ} / \mathrm{mol}, \Delta H^{*}=73.2 \pm 2.3 \mathrm{~kJ} / \mathrm{mol}$

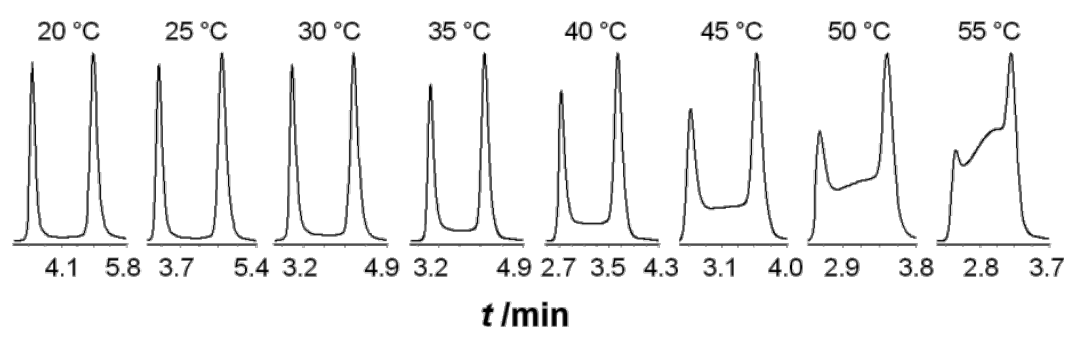

Figure 3: Elution profiles obtained by temperature-dependent DHPLC measurements of 4. 
and $\Delta S^{*}=-68 \pm 4 \mathrm{~J} /(\mathrm{K} \mathrm{mol})\left(\mathrm{R}^{2}=0.9950\right.$, residual deviation $\left.\sigma_{\mathrm{y}}=0.0575\right)$. These data are in very good agreement with the data obtained by conventional reaction progress analysis.

\section{Computational studies}

The rotational barrier was also studied in silico. Therefore, a conformational analysis of $\mathbf{4}$ was performed using the systematic algorithm to search conformers as implemented in Spartan'10 with the semi-empirical PM6 level of theory $[17,18]$. All 2111 resulting conformers were subjected to a DFT geometry optimization at the BP-D3/def2-SVP [19-22] level of theory with ORCA $[23,24]$. The BP functional was chosen because it was found to reproduce the energy difference between the ground states better than B3LYP and PBE for this molecule. With the lowest energy conformer, a potential energy surface (PES) scan for the rotation around the $\mathrm{C}-\mathrm{N}$ bond in steps of $10^{\circ}$ was done. This scan provided two local minima as well as two maxima (Figure 5). The asymmetric peak shape is caused by the inversion of the pyramidal nitrogen between $\phi=110^{\circ}$ and $\phi=120^{\circ}$ as well as $\phi=280^{\circ}$ and $\phi=290^{\circ}$. The geometries of both minima were used as starting geometries for a geometry optimization followed by the calculation of the thermochemical data at $298 \mathrm{~K}$. The coordinates of the maxima were used as starting points for the search for the transition states. After locating the transition state geometries, their thermochemical data at $298 \mathrm{~K}$ were calculated. The PES scan and all subsequent calculations were also performed using COSMO solvation for hexane.

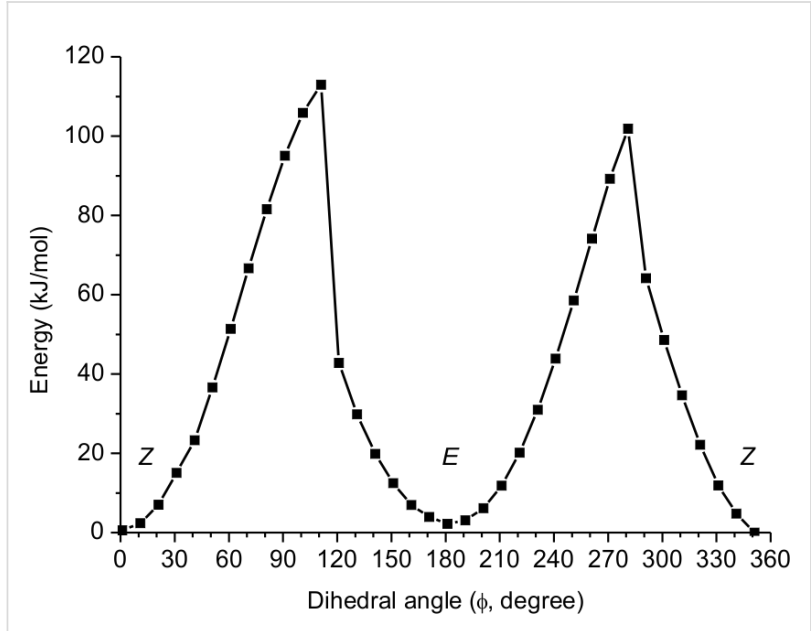

Figure 5: Potential energy surface scan graph for the dihedral angle $\mathrm{O}-\mathrm{C}-\mathrm{N}-\mathrm{C} 1(\phi)$ in 4 (BP-D3/def2-SVP).

The final values for the relative Gibbs free energies for $E-4$, $Z-4$, TS1, and TS2 are given in Table 1 . The difference between the $E$ - and $Z$-isomer of $\mathbf{4}$ is predicted to be $3.2 \mathrm{~kJ} / \mathrm{mol}$ in hexane and $5.8 \mathrm{~kJ} / \mathrm{mol}$ in vacuo, respectively. The transition states are located at $108.8 \mathrm{~kJ} / \mathrm{mol}$ (TS1) and $105.5 \mathrm{~kJ} / \mathrm{mol}$ (TS2) above the $Z$-isomer of 4 for hexane solvation as well as at $107.3 \mathrm{k} / \mathrm{mol}$ (TS1) and $102.1 \mathrm{~kJ} / \mathrm{mol}$ (TS2) in the gas phase, respectively.

Table 1: Relative Gibbs free energy (kJ/mol) for E-4, Z-4, TS1, TS2,

$\mathrm{GS}_{\mathrm{DMF}}, \mathrm{TS} 1_{\mathrm{DMF}}$ and TS2 $\mathrm{DMF}$ in the gas phase and with COSMO solvation for hexane, ethanol and DMSO at $298 \mathrm{~K}$ (BP-D3/def2-SVP).

\begin{tabular}{lllll} 
& gas phase & hexane & ethanol & DMSO \\
\hline Z-4 & 0 & 0 & 0 & 0 \\
TS1 & +107.3 & +108.8 & +109.0 & +110.0 \\
TS2 & +102.1 & +105.5 & +109.8 & +110.4 \\
E-4 & +5.8 & +3.2 & +2.7 & +3.1 \\
GS & 0 & 0 & 0 & 0 \\
TS1 & 0 & +100.8 & +103.7 & +103.9 \\
TS2 & +99.7 & +104.4 & +110.2 & +110.7 \\
\hline
\end{tabular}

The geometries of the $E$ - and $Z$-ground states of $\mathbf{4}$ and both transition states (TS1 and TS2) are shown in Figure 6 together with the dihedral angle $\mathrm{O}-\mathrm{C}-\mathrm{N}-\mathrm{C} 1(\phi)$ and the $\mathrm{C}-\mathrm{N}$ bond length. Both transition states show a single imaginary frequency $\left(-280.8 \mathrm{~cm}^{-1}\right.$ (TS1) and $-364.5 \mathrm{~cm}^{-1}$ (TS2) in hexane and at $-284.0 \mathrm{~cm}^{-1}$ (TS1) and $-362.2 \mathrm{~cm}^{-1}$ (TS2) in the gas phase). This imaginary frequency belongs to the rotational vibration of the formyl hydrogen and the formyl oxygen along the reaction pathway for the $E / Z$ isomerization of 4 . In both transition states geometries, the $\mathrm{C}-\mathrm{N}$ bond $(143 \mathrm{pm})$ is significantly elongated compared to the ground states $(137 \mathrm{pm})$. Furthermore, the nitrogen atom shows a pyramidal instead of a trigonal planar geometry. This reflects the expected decrease of the $\mathrm{C}-\mathrm{N}$ bond order caused by lacking overlap of the $\pi^{*}$-orbital of the carbonyl group and the lone pair at nitrogen.

Unfortunately, the free energy of activation for the rotation of $\mathbf{4}$ is overestimated by at least $10 \mathrm{~kJ} / \mathrm{mol}$. A possible explanation for this difference could be the high basicity of the pyramidal nitrogen in both transition states which may favor the formation of hydrogen bonds lowering the total energy. Other reasons for this overestimation may be an inappropriate representation of the global solvation by the COSMO model or the limited double-zeta basis set, the substitution of which by a larger triple-zeta basis set is too expensive in terms of computational time. Increasing the solvent polarity in COSMO up to pure ethanol or DMSO did however not improve the results. Sulima et al. reported a similar deviation for the calculated rotational barrier in their studies of a morphinan-derived formamide [4] using comparable parameters for their calculations (B3LYP/6$\left.31 \mathrm{G}^{*}\right)$ and obtained a highly similar energy profile.

While in their case only a small energy difference between the $E$ - and the $Z$-ground states was predicted in silico and 


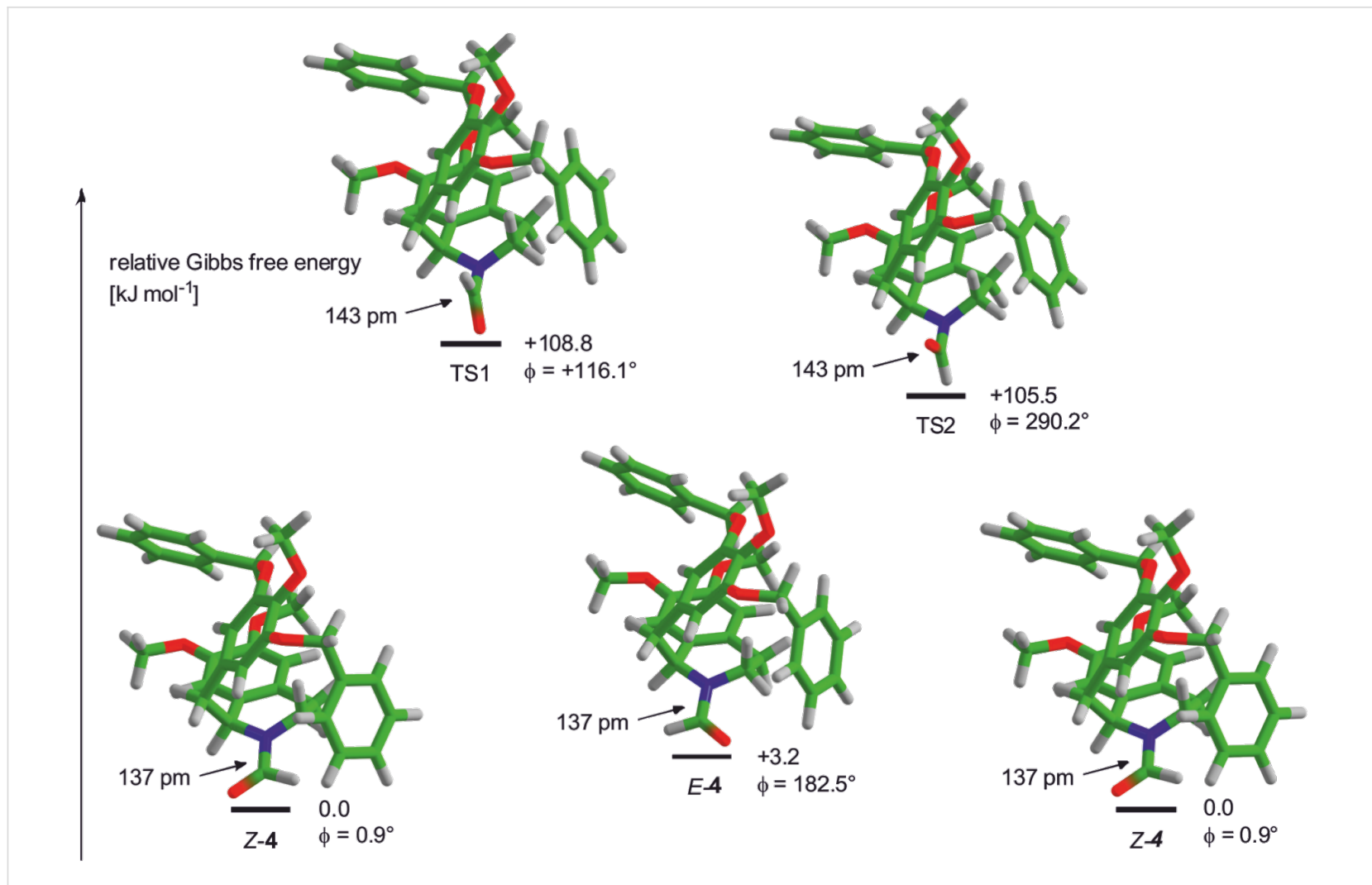

Figure 6: Energy differences and geometries for $E$ - and Z-4 and both transition states (TS1 and TS2) in hexane. The dihedral angle of O-C-N-C1 $(\phi)$ and the C-N bond length are given for each state (BP-D3/def2-SVP).

confirmed experimentally, our DFT results deviate more significantly from the HPLC and NMR data which show the $E$-form and not the $Z$-form to be lower in energy by $0.6-0.8 \mathrm{~kJ} / \mathrm{mol}$. The larger size of the molecule and its considerable conformational freedom may contribute to this deviation. Calculations on the model compound 1-benzyl- $N$-formyl-1,2,3,4tetrahydroisoquinoline at the same level of theory showed that either the $E$ - or the $Z$-ground state can be lower in energy depending on the relative arrangement of the benzyl substituent. For comparison, the rotational barrier for DMF was calculated using the same functional and basis set (Table 1) and was found to be overestimated by $18-22 \mathrm{~kJ} / \mathrm{mol}$ based on $82.6 \mathrm{~kJ} / \mathrm{mol}$ as the value for the experimental barrier in cyclohexane solution [25]. With the B3LYP functional this deviation is reduced to $15-18 \mathrm{~kJ} / \mathrm{mol}$. However, we used the BP functional since the energy difference between the $E$ - and the $Z$-ground states of $\mathbf{4}$ is better reflected.

\section{Conclusion}

The energetic barrier for the rotation about the $\mathrm{C}-\mathrm{N}$-bond of a 1-benzyl- $N$-formyl-1,2,3,4-tetrahydroisoquinoline giving two separable rotamers at $20^{\circ} \mathrm{C}$ was measured using HPLC kinetics as well as dynamic HPLC at variable temperature with good agreement. The latter technique allowed the determination of the enthalpic and entropic contributions for both directions of the interconversion. DFT-calculations overestimated the rotational barrier while dynamic NMR did not prove useful as no signs of coalescence could be detected up to $150{ }^{\circ} \mathrm{C}$. Therefore, dynamic HPLC is a valuable alternative to dynamic NMR and provides full thermodynamic data for reversible interconversions.

\section{Supporting Information}

\section{Supporting Information File 1}

Experimental procedures, HPLC chromatograms, copies of 1D and 2D NMR spectra of compounds 3 and 4 , atom coordinates and DFT energies for ground- and transition states.

[http://www.beilstein-journals.org/bjoc/content/ supplementary/1860-5397-10-63-S1.pdf]

\section{Acknowledgements}

We thank Dr. J. C. Liermann (Mainz) for NMR spectroscopy, the Zentrum für Datenverarbeitung (Mainz) for granting access to the MOGON supercomputer as well as the Naturstoffzentrum Rheinland-Pfalz for helpful discussions. 


\section{References}

1. Rice, K. C.; Brossi, A. J. Org. Chem. 1980, 45, 592-601. doi:10.1021/j001292a008

2. Buchs, P.; Rice, K. C.; Brossi, A.; Silverton, J. V.; Potenzone, R., Jr. J. Org. Chem. 1982, 47, 4134-4137. doi:10.1021/jo00142a025

3. Szántay, C.; Blaskó, G.; Bárczai-Beke, M.; Dörnyei, G.; Radics, L. Heterocycles 1980, 14, 1127-1130. doi:10.3987/R-1980-08-1127

4. Sulima, A.; Cheng, K.; Jacobson, A. E.; Rice, K. C.; Gawrisch, K.; Lee, Y.-S. Magn. Reson. Chem. 2013, 51, 82-88. doi:10.1002/mrc.3909

5. Blank, N.; Opatz, T. J. Org. Chem. 2011, 76, 9777-9784. doi:10.1021/jo201871c

6. Werner, F.; Blank, N.; Opatz, T. Eur. J. Org. Chem. 2007, 3911-3915. doi:10.1002/ejoc.200700261

7. Blank, N.; Straub, B. F.; Opatz, T. Eur. J. Org. Chem. 2011, 7355-7365. doi:10.1002/ejoc.201101183

8. D'Acquarica, I.; Gasparrini, F.; Pierini, M.; Villani, C.; Zappia, G. J. Sep. Sci. 2006, 29, 1508-1516. doi:10.1002/jssc.200600129

9. Trapp, O.; Schoetz, G.; Schurig, V. Chirality 2001, 13, 403-414. doi:10.1002/chir.1052

10. Wolf, C. Chem. Soc. Rev. 2005, 34, 595-608. doi:10.1039/b502508g

11. Trapp, O. Anal. Chem. 2006, 78, 189-198. doi:10.1021/ac051655r

12. Trapp, O. Chirality 2006, 18, 489-497. doi:10.1002/chir.20276

13. Trapp, O.; Bremer, S.; Weber, S. K. Anal. Bioanal. Chem. 2009, 395, 1673-1679. doi:10.1007/s00216-009-2993-4

14. Trapp, O.; Sahraoui, L.; Hofstadt, W.; Könen, W. Chirality 2010, 22, 284-291. doi:10.1002/chir.20742

15. Uray, G.; Jahangir, S.; Fabian, W. M. F. J. Chromatogr., A 2010, 1217 , 1017-1023. doi:10.1016/j.chroma.2009.12.001

16. Trapp, O. J. Chromatogr., B 2008, 875, 42-47. doi:10.1016/j.jchromb.2008.07.047

17. Spartan'10; Wavefunction, Inc.: Irvine, CA, 2011.

18. Stewart, J. J. P. J. Mol. Model. 2007, 13, 1173-1213. doi:10.1007/s00894-007-0233-4

19. Becke, A. D. Phys. Rev. A 1988, 38, 3098-3100. doi:10.1103/PhysRevA.38.3098

20. Perdew, J. P. Phys. Rev. B 1986, 33, 8822-8824. doi:10.1103/PhysRevB.33.8822

21. Weigend, F.; Ahlrichs, R. Phys. Chem. Chem. Phys. 2005, 7, 3297-3305. doi:10.1039/b508541a

22. Grimme, S.; Antony, J.; Ehrlich, S.; Krieg, H. J. Chem. Phys. 2010, 132, 154104. doi:10.1063/1.3382344

23. Neese, F. Wiley Interdiscip. Rev.: Comput. Mol. Sci. 2012, 2, 73-78. doi:10.1002/wcms.81

24. Neese, F.; Wennmohs, F.; Hansen, A.; Becker, U. Chem. Phys. 2009, 356, 98-109. doi:10.1016/j.chemphys.2008.10.036

25. Wiberg, K. B.; Rablen, P. R.; Rush, D. J.; Keith, T. A. J. Am. Chem. Soc. 1995, 117, 4261-4270. doi:10.1021/ja00120a006

\section{License and Terms}

This is an Open Access article under the terms of the Creative Commons Attribution License

(http://creativecommons.org/licenses/by/2.0), which permits unrestricted use, distribution, and reproduction in any medium, provided the original work is properly cited.

The license is subject to the Beilstein Journal of Organic Chemistry terms and conditions:

(http://www.beilstein-journals.org/bjoc)

The definitive version of this article is the electronic one which can be found at:

doi:10.3762/bjoc. 10.63 